\title{
Therapeutic Perspectives on the Treatment of Urticaria Associated with Angioedema
}

\author{
Sur Genel ${ }^{1,2 *}$, Floca Emanuela ${ }^{1}$, Lucia Sur ${ }^{1}$, Daniel Sur ${ }^{1}$ and Samasca Gabriel ${ }^{1,2}$ \\ ${ }^{1}$ University of Medicine and Pharmacy, Iuliu Hatieganu, Cluj-Napoca, Romania \\ ${ }^{2}$ Emergency Clinical Hospital for Children, Cluj-Napoca, Romania
}

\begin{abstract}
Urticaria is common in pathology. Urticaria and angioedema with persistent symptoms have a significant effect on quality of life and activity. Typical manifestations of urticaria are not difficult to diagnose. Association of urticaria with angioedema is relatively common, about $50 \%$ of cases. This association can be life-threatening requiring intensive care. Urticaria treatment is not easy and when angioedema associated therapeutic measures should be complex. Etiological treatment is the most desirable option for physician and patient, but in many cases the cause cannot be identified. Non-sedating $\mathrm{H}_{1}$-antihistamines are considered first-line treatment of urticaria.
\end{abstract}

Keywords: Urticaria; Angioedema; Allergy

\section{Introduction}

Allergic manifestations have become more and more frequent lately. Urticaria with or without angioedema is a common skin disorder with different levels of severity. Recognizing of different forms of urticaria and angioedema is very important for making the correct diagnosis and best treatment.

Urticaria is characterized by the sudden appearance of acute or chronic pruritic wheals. The lesions consist of red, raised, itchy circumscribed areas of dermal edema that usually are multiple and vary in size and form. Each individual lesion lasts for a few hours, while new lesions appear in other areas.

Angioedema is defined as sudden severe edema of the deeps dermis and subcutaneous and submucosal tissue. Lesions of angioedema can persist for 72 hours. Angioedema causes severe swelling, usually in the face, lips, eyelids and genitalia. Occasionally the tongue and laryngopharynx are also involved, which is a dangerous situation because it can close off the passage of air into the lungs [1-4].

\section{Classification of Urticaria}

Urticaria

$\checkmark$ Spontaneous urticaria:

- Acute

- Chronic

$\checkmark$ Physical urticaria:

- Dermographism

- Delayed pressure urticaria

- Cold urticaria

- Solar urticaria

- Aquagenic urticaria

- Vibratory urticaria

$\checkmark$ Other types of urticaria

- Cholinergic urticaria

- Contact urticaria

- Exercise induced urticaria

Urticaria and angioedema may be classified by duration and trigger factors. Urticaria is classified as acute and chronic. Lesions of acute urticaria last less than six weeks. If wheals last for more than six weeks, the urticaria can be termed chronic.
Appearance of linear wheal at site of brisk stroke with firm object characterized dermographism. Wheals in delayed pressure urticaria occur after 4-6 hours at places of sustained pressure applied to the skin. In physical urticaria the application of a physical stimulus (cold water/air, 2800-5000 $\AA$ wavelength of sunlight, vibratory forces) to the skin causes the formation of local wheals. Large hives induced by exercise alone suggest exercise-induced urticaria and punctuate wheals associated with exposure to heat; exercise and anxiety characterized cholinergic urticaria $[1,5,6]$.

Of the types of angioedema associated with urticaria mention the following $[1,5]$ :

$\checkmark$ Allergic angioedema;

$\checkmark$ NSAID-induced angioedema;

$\checkmark$ Angioedema occurred within infections and infestations;

$\checkmark$ Angioedema associated with some physical urticarias;

$\checkmark$ Angioedema with allergic contact urticaria.

\section{Pathogenesis}

Acute urticaria may involve both immune and non-immune pathways. Histamine is the main mediator of urticaria. In allergic rashes caused by foods, medications, and insect bites histamine is produced by immune-mediated mechanism mediated by IgE. IgE antibodies bind to specific receptors of mast cells causing histamine release. Urticaria caused by non-immune mechanism is found in physical urticaria such as dermographism, delayed pressure urticaria, cold urticaria, solar urticaria, aquagenic urticaria and vibratory urticaria. Mast cells and basophils are effector cells involved in causing urticaria. These cells release vasoactive substances represented by histamine, bradykinin, leukotriene C4, prostaglandin D2. These substances cause

*Corresponding author: Sur Genel, University of Medicine and Pharmacy, luliu Hatieganu, Cluj-Napoca, Romania, E-mail: surgenel@yahoo.com

Received October 09, 2012; Accepted November 12, 2012; Published November 15,2012

Citation: Genel S, Emanuela F, Sur L, Sur D, Gabriel S (2012) Therapeutic Perspectives on the Treatment of Urticaria Associated with Angioedema. Pharmaceut Anal Acta 3:187. doi:10.4172/2153-2435.1000187

Copyright: $\odot 2012$ Genel S, et al. This is an open-access article distributed unde the terms of the Creative Commons Attribution License, which permits unrestricted use, distribution, and reproduction in any medium, provided the original author and source are credited. 
vasodilatation and increased vascular permeability. This produces erythema and edema leading to urticaria lesions. Itching, an important feature of urticaria is mediated by histamine receptors as erythema and flushing $[7,8]$.

\section{Etiology}

A specific etiology can be identified in only $50 \%$ of patients with acute urticaria.

Drugs: A list of drugs, such as antibiotics (penicillin, cephalosporin, macrolides, vancomycin), NSAIDs, opiates, narcotics can cause acute urticaria with or without angioedema. Most common mechanism of urticaria related to drug administration is non-allergic mechanism, but with IgE`s participation.

Food allergens: The most common food products involved in the appearance of urticaria in young children are milk, eggs, wheat, soy and peanuts. Other food allergens involved in causing urticaria in older children are peanuts, tree nuts, seafood and shellfish.

Environmental allergens: Potential environmental allergens trigger hives include dust mites, molds and animal dander.

Insects: Urticarial lesions may result from insect bite or sting. The most common are bites of mosquitoes, bees and spiders.

Systemic diseases: Systemic diseases associated with urticaria and angioedema include infectious, autoimmune diseases and malignancies. In children, viral infections are considered to be the most common cause of acute urticaria.

Physical urticaria: Physical stimuli include the following: cold, heat, scratch, pressure, vibration. Dermatographism is the most common physical urticaria.

Idiopathic causes: In acute urticaria the trigger is often revealed. Most chronic urticarias are idiopathic [9-13].

\section{Epidemiology}

Episodes of urticaria and angioedema in children are usually mild but can cause significant discomfort depending on the severity. Urticaria affects $15 \%$ to $25 \%$ of the population at some point in their lifetime. The prevalence in preschool children is $6 \%$ to $7 \%$. Both urticaria and angioedema occur concomitantly in $50 \%$ of patients, $40 \%$ have only urticaria, and 10\% have isolated angioedema [1-4].

The II Pediatric Clinic's cases, from January 2011 until January 2012, have noted 1180 patients who presented different allergic manifestations of teguments, representing $18 \%$ out of the total of 6400 patients that were interned over the course of that year. Urticaria caused by food was diagnosed in $35 \%$ of the 1180 allergic patients, meaning 436 patients. The rest of the urticarial manifestations appeared as results of infections, medicine use or specific disease. Of the patients with urticaria, 51\%, meaning 601 patients, also presented angioedema manifestations. To identify the allergens, the specific IgE pediatric panel was made for 20 allergens.

\section{Clinical Presentation}

Physical examination of the patient is an important step for diagnosis. Hives appear as papular erythematous blanching lesions. These lesions appear suddenly and may cover all or part of the body, but not mucosal surfaces. Each wheal may last from a few minutes to six hours. While some lesions disappear, new ones arise. They can be of any size and various forms. Most often they are round or oblong. Linear lesions suggest dermographysm. Hives are patchy at first. Evolving, patches can be merged until the rash covers most of the body. The patches have a central blanched area surrounded by a red halo. An important feature of urticaria is itching, which can often be very intense. Rarely patients can experience pain. Skin rash remission should be no residual pigmentary changes.

Urticaria may be associated or not with angioedema. Angioedema is characterized by marked swelling especially around the eyes and mouth. Due to marked edema the eyes may appear swollen shut. It can involve the extremities, the genitalia, so swelling can occur anywhere. Mucosal tissue edema in severe cases may involve the tongue, throat, and larynx causing dyspnea and acute respiratory failure. Acute allergic angioedema may develop with anaphylaxis in which case signs and symptoms of shock become manifest. Angioedema usually is not accompanied by itching. If there angioedema patients experience pain, sensation of pressure and burning [14-18].

\section{Diagnostic Approach}

Diagnosis of urticaria and angioedema is based on detailed medical history paying attention to potential trigger factors. The most common trigger factors are allergies, atopic disease, medication use, sign and symptoms of infection. Family history of atopy (allergic rhinitis, asthma, and aspirin allergy), angioedema, autoimmune, and thyroid disease should not be overlooked. It is important to know about the onset of symptoms, presence or absence of itching, pain and heat. Another important step for diagnosis is physical examination. Characteristic appearance and evolution of urticaria lesions turn to a correct diagnosis.

IgE measurement and skin tests may be useful in patients with suspected food allergies or inhalant allergies. In most cases of chronic urticaria with angioedema major objective of the evaluation is to exclude underlying diseases. In these cases laboratory tests include: complete blood count, chemistry panel, erythrocyte sedimentation rate, antinuclear antibody, and urinalysis. Other diagnostic testing discussed are thyroid function, skin biopsy, presence or absence of rheumatoid factor $[1,15,19]$.

\section{Differential Diagnosis}

Atopic dermatitis: Diagnostic criteria for atopic dermatitis include the following: pruritus, early age of onset, chronic and relapsing course and history of atopy.

Contact dermatitis: A detailed medical history that will pay attention to environmental exposures guide the clinician to the correct diagnosis. In acute urticaria lesions seem to be a vesicular eruption. It progress to chronic contact dermatitis with continued allergenic exposure. This skin disorder is characterized by minimal edema, scaling, fissuring and lichenification.

Systemic mastocytosis: Patients with systemic mastocytosis may present with episodic systemic flushing and pruritus if there are cutaneous abnormalities.

Urticarial vasculitis: Is characterized by an urticarial eruption. This may be associated with normo- or hypocomplementemia, angioedema, arthralgias, abdominal or chest pain, pulmonary disease, episcleritis, uveitis.

Serum sickness: Common symptoms of serum sickness include fever and urticarial rashes. 
Drug eruption: Most drug reactions are exanthematous. There are severe reactions manifested by angioedema, mucous membrane erosion, blisters, Nikolsky sign, confluent erythema and skin necrosis $[16,17,20]$.

\section{Treatment}

The main goal of treatment for urticaria with or without angioedema is to achieve complete symptom relief. First step in management is to identify and eliminate triggers of urticaria, and the second directed medical treatment to relieve symptoms. Treating the cause is the most desirable option for both patient and clinician but it is not applicable in all cases. Avoidance of triggers and stimulus can be initiated in patients with IgE mediated urticaria and physical urticaria. The treatment of associated infectious and inflammatory disease, including gastritis, bacterial sinusitis and parasitic, should not be skipped.

The treatment of urticaria with or without angioedema depends on the severity of symptoms. Acute urticaria with angioedema may develop life-threatening airway obstruction. If angioedema affects the respiratory tract, the first step should be securing airway. There are cases where intubation or tracheostomy is required. To reduce edema subcutaneous or intramuscular adrenaline is indicated $[1,15,21]$.

\section{Medications}

\section{$H_{1}$ antagonists}

First-line treatment for both acute and chronic urticaria is anti- $\mathrm{H}_{1}$ antihistamines. Most symptoms of urticaria are mediated by $\mathrm{H}_{1}$ receptors located on nerves and endothelium. $\mathrm{H}_{1}$-receptor antagonists are most effective in treating urticaria although not all patients respond.

First generation antihistamines because of anticholinergic effects and sedative actions are not recommended for the management of various kinds of urticaria.

New generation of antihistamines include drugs that are minimally sedating and non cholinergic effects. Thus the new generation of antihistamines is considered first-line treatment of urticaria. The most common second-generation antihistamines are: levocetirizine, desloratadine, loratadine and fexofenadine. The effect of second generation antihistamines is dose-dependent and important aspect is that they do not produce side effects at high doses. Two other important features of second-generation antihistamines are rapid onset and long duration of action. Patients with chronic urticaria can use second generation antihistamines in a single daily dose preferably given at bedtime. In patients treated with second-generation antihistamines has been shown to reduce the intensity of itching and wheals [1,22-24].

\section{$\mathrm{H}_{2}$ antagonists}

$\mathrm{H}_{2}$ antagonists are not effective as monotherapy in hives. $\mathrm{H}_{2}$ antagonists including ranitidine and cimetidine in combination with and $\mathrm{H}_{1}$ antagonist has been shown to be more effective than an $\mathrm{H}_{1}$ antagonist alone. These agents are used to reduce gastric acid secretion $[16,18]$.

\section{Corticosteroids}

The EAACI/GA ${ }^{2}$ LEN/EDF/WAO management guideline recommends the use of corticosteroids only in severe cases.

Short-term corticosteroid therapy may reduce urticaria. It can be given in acute urticaria unresponsive to antihistamines and exacerbations of chronic spontaneous urticaria. These agents help to relieve symptoms such as swelling and inflammation and also reduce the likelihood of relapse $[1,15,18]$.

\section{Sympathomimetic agents}

Intravenous epinephrine should be administered to patients with airway obstruction, acute respiratory failure or shock $[25,26]$.

\section{Other agents}

There are some data suggesting that the combination of leukotriene receptor antagonists to therapy with antihistamines be effective for some patients [27-29].

Cyclosporine therapy is initiated only in cases refractory to treatment with high dose antihistamines. It may be useful in patients with autoimmune chronic urticaria. Intravenous immunoglobulins (IVIG), plasmapheresis and antagonists of tumor necrosis factor a (TNFa) are recommended only to be initiated by specialists for patients with severe diseases [1].

Other therapies used but include sulfasalazine, hydroxychloroquine, methotrexate, tacrolimus, danazol, colchicine, dapsone, and cyclophosphamide [1,30].

Omalizumab is a therapeutic alternative for patients with chronic spontaneous urticaria, cholinergic urticaria, cold urticaria and solar urticaria [31].

Symptomatic treatment of acute urticaria is second generation antihistamine monotherapy lasting for 2-3 weeks. In severe cases it can be associated with a short course of corticosteroids.

In patients with chronic urticaria second generation antihistamines can be administered up to 4 doses daily. Therapeutic alternatives are represented by adding montelukast, hydroxychloroquine, dapsone, oral glucocorticosteroids, cyclosporine A [1,29].

Treatment of dermographysm is that for spontaneous chronic urticaria and consists of second generation antihistamines.

Antihistamines are not effective in delayed-pressure urticaria. In severe cases, oral corticosteroids are associated.

For patients with physical urticaria forms $\mathrm{H}_{1}$ antihistamines oh new generation are the first choice of treatment. To achieve remission of cold urticaria can be given oral doxycycline or penicillin intramuscularly. For patients with solar urticaria therapeutic possibilities include: plasmapheresis, cyclosporine A, hydroxychloroquine [7,9].

Special forms of urticaria refer to: cholinergic urticaria, exerciseinduced urticaria and aquagenic urticaria. In these types of urticaria second generation of antihistamines are administered regularly or before a typical situation [1] (Table 1).

\begin{tabular}{|c|c|c|c|}
\hline Group of urticaria & Subtypes & Treatment & \\
\hline Spontaneous urticaria & Acute urticaria & $\begin{array}{l}> \\
>\end{array}$ & $\begin{array}{l}\text { Non-sedating } \mathrm{H} 1 \text {-antihistamines } \\
\text { Severe cases: urticaria associated with angioedema }- \text { Glucocorticosteroids } \\
(0.5-1 \mathrm{mg} / \mathrm{Kg} / \mathrm{day}) ; \\
\text { anaphylactic shock - Epinephrine } \quad(0.01 \mathrm{mg} / \mathrm{Kg} / \mathrm{dose})\end{array}$ \\
\hline
\end{tabular}


Citation: Genel S, Emanuela F, Sur L, Sur D, Gabriel S (2012) Therapeutic Perspectives on the Treatment of Urticaria Associated with Angioedema. Pharmaceut Anal Acta 3:187. doi:10.4172/2153-2435.1000187

Page 4 of 5

\begin{tabular}{|c|c|c|c|}
\hline & Chronic urticaria & $\begin{array}{l}> \\
> \\
>\end{array}$ & $\begin{array}{l}\text { Non-sedating H1-antihistamines } \\
\text { (up to } 4 \text { doses daily) } \\
\text { Non-sedating H1-antihistamines may be associated with: } \\
-\quad \text { Montelukast } \\
-\quad \text { Hydroxychloroquine } \\
-\quad \text { Dapsone } \\
-\quad \text { Oral glucocorticosteroids } \\
\text { - Cyclosporine A } \\
\text { - } \quad \text { Plasmapherezis } \\
-\quad \text { Intravenous immunoglobulins } \\
\text { - Omalizumab }\end{array}$ \\
\hline \multirow[t]{6}{*}{ Physical urticaria } & Dermographism & $>$ & $\begin{array}{l}\text { Non-sedating } \mathrm{H} 1 \text {-antihistamines } \\
\text { alternative therapeutic: options for treatment of }\end{array}$ \\
\hline & Delayed pressure urticaria & $>$ & $\begin{array}{l}\text { Non-sedating } \mathrm{H} 1 \text {-antihistamines -high dose } \\
\text { Other treatment options: } \\
\text { - Non sedating } \mathrm{H} 1 \text {-antihistamines + Montelukast } \\
\text { - Non sedating } \mathrm{H} 1 \text {-antihistamines + glucocorticosteroids }\end{array}$ \\
\hline & Cold urticaria & $>$ & $\begin{array}{l}\text { Non-sedating } \mathrm{H} 1 \text {-antihistamines } \\
\text { Penicillin i.m./p.o. } \\
\text { Docycyline p.o. } \\
\text { Omalizumab }\end{array}$ \\
\hline & Solar urticaria & $\begin{array}{l}> \\
>\end{array}$ & $\begin{array}{l}\text { Non-sedating } \mathrm{H} 1 \text {-antihistamines } \\
\text { Other treatment options: } \\
\text { Plasmapheresis+PUVA } \\
\text { Intravenous immunoglobulins } \\
\text { Omalizumab } \\
\text { Cyclosporine A, Hydroxychloroquine }\end{array}$ \\
\hline & Aquagenic urticaria & $>$ & Non-sedating $\mathrm{H} 1$ - antihistamines in increased dose ( regularly or as needed) \\
\hline & Vibratory urticaria & Avoidance & \\
\hline \multirow[t]{3}{*}{ Other types of urticaria } & Cholinergic urticaria & $\begin{array}{l}> \\
>\end{array}$ & $\begin{array}{l}\text { Non-sedating } \mathrm{H} 1 \text { - antihistamines in increased dose ( regularly or as needed) } \\
\text { Omalizumab } \\
\text { Danazol }\end{array}$ \\
\hline & Contact urticaria & $>$ & Non-sedating $\mathrm{H} 1$ - antihistamines in increased dose ( regularly or as needed) \\
\hline & Exercise induced urticaria & $>$ & Non-sedating $\mathrm{H} 1$ - antihistamines in increased dose ( regularly or as needed) \\
\hline
\end{tabular}

Table 1: Treatments in urticaria $[1,24]$

\section{References}

1. Zuberbier T, Asero R, Bindslev-Jensen C, Walter Canonica G, Church MK, et al. (2009) EAACI/GA(2)LEN/EDF/WAO guideline: definition, classification and diagnosis of urticaria. Allergy 64: 1417-1426.

2. Marrouch N, Grattan C (2012) Childhood urticaria. Curr Opin Allergy Clin Immunol 12: 485-490.

3. Kanani A, Schellenberg R, Warrington R (2011) Urticaria and angioedema. Allergy Asthma Clin Immunol 7: S9.

4. Axelrod S, Davis-Lorton M (2011) Urticaria and angioedema. Mt Sinai J Med 78: 784-802

5. Kontou-Fili K, Borici-Mazi R, Kapp A, Matjevic LJ, Mitchel FB (1997) Physical urticaria: classification and diagnostic guidelines. Allergy 52: 504-513.

6. Atkins FM (1991) Food induced urticaria. In: Metcalfe DD, Sampson HA, Simon RA (eds). Food allergy: adverse reactions to food and food additives. Blackwell Scientific Publication, Oxford 129-138.

7. Kaplan A (2004) Urticaria and angioedema. Pathogenic mechanisms and treatment. JACl 114: 415-424.

8. AJ Bircher (1999) Drug induced urticaria and angioedema caused by non-lgE mediated pathomechanisms. Eur J Dermatol 9: 657-663.

9. Torchia D, Francalanci S, Bellandi S, P Fabbri (2008) Multiple physical urticarias. Postgrad Med J 84: e1-e2.

10. Sackesen C, Sekerel BE, Orhan F, Kocabas CN, Tuncer A, et al. (2004) The etiology of different forms of urticaria in childhood. Pediatr Dermatol 21: 102108.

11. Sicherer SH, Leung DY (2008) Advances in allergic skin disease, anaphylaxis, and hypersensitivity reactions to foods, drugs, and insects in 2007. J Allergy Clin Immunol 121: 1351-1358.

12. Black AK (2004) Physical urticarias and cholinergic urticaria. In: Greaves MW
Kaplan AK, editors. Urticaria and angioedema. New York: Marcel Dekker 171 214

13. Wedi B, Raap U, Wieczorek D, Kapp A (2009) Urticaria and infections. Allergy Asthma Clin Immunol 5:10.

14. Zuberbier T, Iffländer J, Semmler C, Henz BM (1996) Acute urticaria: clinical aspects and therapeutic responsiveness. Acta Derm Venereol 76: 295-297.

15. Grattan $\mathrm{CEH}$, Humphreys $\mathrm{F}$ (2007) on behalf of the British Association of Dermatologists Therapy Guidelines and Audit Subcommittee. Guidelines for evaluation and management of urticaria in adults and children. $\mathrm{Br} \mathrm{J}$ Dermato 157: 1116-1123.

16. Frigas E, Park MA (2009) Acute urticaria and angioedema: diagnostic and treatment considerations. Am J Clin Dermatol 10: 239-250.

17. Wedi B, Kapp A (2007) Urticaria and angioedema. In: Mahmoudi M: Allergy: Practical Diagnosis and Management. New York, USA, Mc Graw Hill 84-94.

18. Schaefer P (2011) Urticaria: evaluation and treatment. Am Fam Physician 83 1078-1084.

19. Maloney JM, Rudengren M, Ahlstedt S, Bock SA, Sampson HA (2008) The use of serum specific lgE measurements for the diagnosis of peanut, tree nut, and seed allergy. J Allergy Clin Immunol 122: 145-151.

20. Butterfield JH (2006) Systemic mastocytosis: clinical manifestations and differential diagnosis. Immunol Allergy Clin North Am 26: 487-513.

21. Sheila MA, Stephen CD (2008) Urticaria. Prim Care Clin Office Pract 35: 141 157.

22. Staevska M, Popov TA, Kralimarkova T, Lazarova C, Kraeva S, et al. (2010) The effectiveness of levocetirizine and desloratadine in up to 4 times conventional doses in difficult-to-treat urticaria. J Allergy Clin Immunol 125: 676-682.

23. Slater JW, Zechnich AD, Haxby DG (1999) Second-generation antihistamines: a comparative review. Drugs 57: 31-47. 
Citation: Genel S, Emanuela F, Sur L, Sur D, Gabriel S (2012) Therapeutic Perspectives on the Treatment of Urticaria Associated with Angioedema. Pharmaceut Anal Acta 3:187. doi:10.4172/2153-2435.1000187

Page 5 of 5

24. Ortonne JP (2012) Urticaria and its subtypes: the role of second-generation antihistamines. Eur J Intern Med 23: 26-30.

25. Sur Genel (2012) Epinephrine Can Save Lives. Anaphylaxis, always a Challenge: A Therapeutic Approach on Children J Aller Ther 3: 1.

26. Sadana A, O'Donnell C, Hunt MT, Gavalas M (2000) Managing acute anaphylaxis. Intravenous adrenaline should be considered because of the urgency of the condition. BMJ 320: 937-938.

27. Di Lorenzo G, Pacor ML, Mansueto P, Esposito-Pellitteri M, Ditta V, et al. (2006) Is there a role for antileukotrienes in urticaria? Clin Exp Dermatol 31: 327-334.
28. Berkun Y, Shalit M (2000) Successful treatment of delayed pressure urticaria with montelukast. Allergy 55: 203-204.

29. McBayne TO, Siddall OM (2006) Montelukast treatment of urticaria. Ann Pharmacother 40: 939-942.

30. Boehm I, Bauer R, Bieber T (1999) Urticaria treated with dapsone. Allergy 54 765-766.

31. Spector SL, Tan RA (2009) Advances in allergic skin disease: omalizumab is a promising therapy for urticaria and angioedema. J Allergy Clin Immunol 123: 273-274. 